\title{
No Interacting Influence of Lavender Oil Preparation Silexan on Oral Contraception Using an Ethinyl Estradiol/Levonorgestrel Combination
}

\author{
Doris Heger-Mahn • Günther Pabst • \\ Angelika Dienel · Sandra Schläfke • \\ Christine Klipping
}

Published online: 16 October 2014

(C) The Author(s) 2014. This article is published with open access at Springerlink.com

\begin{abstract}
Purpose Silexan is an oral Lavender oil preparation with proven anxiolytic efficacy. Given the high prevalence of anxiety and restlessness in younger women, oral contraceptives and Silexan will likely be co-administered.

Methods A double-blind, randomised, 2-period crossover study was performed to investigate the effects of Silexan on the pharmacokinetics and pharmacodynamics of Microgynon ${ }^{\circledR}$, a combination oral contraceptive containing ethinyl estradiol $0.03 \mathrm{mg}(\mathrm{EE})$ and levonorgestrel $0.15 \mathrm{mg}$ (LNG) in healthy, fertile, adult females. During 2 consecutive cycles of 28 days, oral contraception was given for 21 days combined with $1 \times 160 \mathrm{mg} /$ day Silexan or placebo. Plasma concentration-time profiles of EE and LNG were obtained on day $18 \pm 1$ up to $24 \mathrm{~h}$ after dosing. The primary outcome measure was the area under the concentration-time curve over a dosing interval of $\tau=24 \mathrm{~h}$ (AUC $\tau$ ) for EE and LNG plasma levels. An interaction with Silexan was formally
\end{abstract}

Trial registration: ISRCTN52706881, International Standard Randomised Controlled Trial Number Register.

D. Heger-Mahn

Dinox GmbH Female Health Research, Anklamer Straße 38,

10115 Berlin, Germany

e-mail: doris.hegermahn@dinox.de

G. Pabst

Formerly Focus CDD GmbH, Stresemannallee 6, 41460 Neuss, Germany

\author{
A. Dienel $(\bowtie) \cdot S$. Schläfke \\ Willmar Schwabe GmbH \& Co. KG, Willmar-Schwabe-Straße \\ 4, 76227 Karlsruhe, Germany \\ e-mail: angelika.dienel@schwabe.de \\ C. Klipping \\ Dinox B. V., Hanzeplein 1, ingang 53, 9713 GZ Groningen, \\ The Netherlands
}

excluded if the $90 \%$ confidence interval for the AUC $\tau$ ratio during co-administration with Silexan or placebo was included within the range of $0.80-1.25$. Secondary outcomes included EE and LNG peak concentration $\left(C_{\max }\right)$ and time to $C_{\max }\left(t_{\max }\right)$, follicle size, endometrial thickness, the Hoogland score, and serum levels of estradiol, progesterone, and sex hormone-binding globulin.

Results A total of 24 women (mean age 27.3 years; mean body mass index $22.2 \mathrm{~kg} / \mathrm{m}^{2}$ ) participated. The confidence intervals for the EE and LNG AUC $\tau$ and $C_{\max }$ ratios fell within the pre-specified limits, indicating no interaction (point estimates [Silexan/placebo] AUC $\tau$ EE 0.97, LNG 0.94; $C_{\max }$ EE 0.99, LNG 0.96). For LNG, $t_{\max }$ was slightly delayed. No secondary outcome indicated any impairment of contraceptive efficacy.

Conclusions Co-administration of Silexan did not affect the efficacy of a combination oral contraceptive containing EE and LNG and was well tolerated.

\section{Key Points}

Due to the high prevalence of anxiety and restlessness in younger women, the herbal anxiolytic drug Silexan and oral contraceptives are likely to be co-administered. Therefore, it is important to investigate the interaction potential of Silexan with oral contraceptives.

This randomised, double-blind, placebo-controlled crossover trial showed that Silexan did not relevantly affect the pharmacokinetic properties of a combination oral contraceptive containing ethinyl estradiol and levonorgestrel.

Silexan therefore does not decrease the efficacy of currently used combination oral contraceptives. 


\section{Introduction}

Silexan ${ }^{1}$ is a preparation from Lavandula angustifolia for oral use that is obtained from the flowering tops of the plant by steam distillation, and that complies with the monograph Lavender oil of the European Pharmacopoeia [1] with respect to all quality parameters. It exceeds the quality definition of the pharmacopoeial monograph with respect to items that are important for efficacy and tolerability. Randomised controlled clinical trials have demonstrated that Silexan is a potent anxiolytic drug with superior efficacy compared with placebo in subsyndromal anxiety disorder [2]. In generalised anxiety disorder (GAD), Silexan was found to be comparably efficacious as lorazepam [3] and at least as efficacious as paroxetine. The drug has a marketing authorisation in Germany for the symptomatic treatment of restlessness related to anxious mood, with a recommended dosage of $80 \mathrm{mg} / \mathrm{d}$. While Silexan is a complex, multiingredient mixture, its anxiolytic properties have been ascribed in particular to linalool and linalyl acetate [4].

Anxiety disorders are by far the most prevalent psychiatric conditions in Western Europe and the USA [5, 6]. Their prevalence in women is at least twice as high as in men $[7,8]$. Since the prevalence of anxiety disorders tends to decrease rather than to increase with age [9], a substantial proportion of the patients who seek treatment for anxiety are women of childbearing potential who may be practising oral contraception.

The steroid hormones contained in oral contraceptives are metabolised mainly through hydroxylation in the liver. Drugs that induce the cytochrome P450 (CYP) enzyme system, notably CYP3A4, reduce the bioavailability by increasing the first-pass metabolism of the oral contraceptive steroids and may therefore impair their efficacy, leading to breakthrough bleeding and, possibly, unwanted pregnancy $[10,11]$. A comprehensive list of drugs that induce CYP has been published by Rendic [12]. They include several anticonvulsants and broad spectrum antibiotics, rifampicin, griseofulvin, and anti-retroviral drugs.

Bioavailability is the rate and extent to which the active substance or active moiety is absorbed from a pharmaceutical form and becomes available at the site of action [13]. As the use of herbal preparations increases in the general population, the potential for herb-drug interactions also increases. Therefore, herbal products must be assessed for their efficacy and safety, including their potential for interactions with other drugs [14]. Since women of childbearing potential who practise oral contraception represent an important part of the target population for which Silexan is intended, it is important to investigate whether the herbal

\footnotetext{
${ }^{1}$ Silexan is the active substance of Lasea ${ }^{\circledR}$, manufacturer: Dr. Willmar Schwabe GmbH \& Co. KG, Karlsruhe, Germany.
}

drug may have an effect on the bioavailability and efficacy of oral contraceptives. Although a clinical study showed no induction of the CYP enzymes 1A2, 2C9, 2C19, 2D6 and 3A4 [15], suggesting that no increased activity in metabolization of contraceptive ingredients occurs during coadministration of Silexan, some examples of inhibition of phase-II enzymes, mainly UDP-glucuronosyltransferases (UGTs), by co-administered herbal drugs (e. g., Williams et al. [16]) do exist. This study was therefore performed to investigate the relative bioavailability of ethinyl estradiol (EE) and levonorgestrel (LNG), the active ingredients of the monophasic combination oral contraceptive Microgynon ${ }^{\circledR}$, during co-administration of Silexan as compared with the administration of the oral contraceptive alone, as well as any attenuating effect on contraceptive efficacy.

\section{Experimental Procedures}

\subsection{Protocol and Design, Objectives}

The investigation was performed as a double-blind, randomised, placebo-controlled, monocentric, crossover study in healthy volunteers whose primary objective was to assess the interacting potential of Silexan with the pharmacokinetic properties of EE and LNG, the active ingredients of the combination oral contraceptive Microgynon ${ }^{\circledR}$. An important secondary objective was to assess whether Silexan had an effect on the suppressive efficacy of Microgynon ${ }^{\circledR}$ on hormonal and ovarian status.

The protocol was reviewed and approved by an independent ethics committee. All subjects provided written informed consent. The principles of Good Clinical Practice and the Declaration of Helsinki were adhered to.

\subsection{Participants}

The study participants were healthy, female, premenopausal volunteers aged between 18 and 38 years (smokers had to be $\leq 30$ years of age, and those with a consumption of more than ten cigarettes per day were excluded), who presented with a body mass index between 18 and $30 \mathrm{~kg} /$ $\mathrm{m}^{2}$. For eligibility for randomised treatment, subjects had to take Microgynon ${ }^{\circledR}$ for at least 2 cycles before randomisation, with a 'usual' 28-day pill cycle and withdrawal bleedings during the 7-day pill-free interval. Eligible subjects were also required to use a non-hormonal method of contraception in addition to Microgynon ${ }^{\circledR}$ throughout the study period. Women with delivery, abortion, or lactation within 3 months of the study were excluded.

During study participation, the subjects were not allowed to take any of the following drugs: any drugs known or discussed to potentially induce liver enzymes 
(e.g. rifampicin, dexamethasone, barbiturates, anticonvulsants, St. John's wort); any drugs known to inhibit CYP3A4 (e.g. ketoconazole, verapamil, cimetidine, macrolides); any broad-spectrum antibiotics; and long-acting, injectable or implant hormonal therapy within 26 weeks prior to the screening visit, as well as any oral contraceptives other than the investigational treatment.

\subsection{Interventions, Blinding}

Silexan was presented in immediate-release soft gelatine capsules containing $160 \mathrm{mg}$ of lavender oil. An identically matched placebo was available in which the smell of the study drug was concealed by flavouring the capsules with $0.08 \mathrm{mg}$ of Lavender oil, i.e., with 1/2000 of the amount of Lavender oil contained in the active capsules. During randomised treatment, the subjects had to take one capsule of Silexan or placebo per day in the morning unchewed. A daily dose of $160 \mathrm{mg}$ corresponds to twice the currently recommended dose of the marketed product. Moreover, Silexan $160 \mathrm{mg} /$ day has been shown to be highly efficacious in patients with GAD [17].

Microgynon $^{\circledR}$ is a combination oral contraceptive containing $0.03 \mathrm{mg}$ of $\mathrm{EE}$ and $0.15 \mathrm{mg}$ of $\mathrm{LNG}$ in a coated tablet. The drug is widely used in combination oral contraceptive interaction studies [18, 19] and was packed in the original marketed package, which carried an additional label presenting the information required for use in a clinical trial. Starting on the first day of each cycle during study participation, subjects were instructed to take one coated tablet per day in the morning for 21 consecutive days, followed by a 7-day break; during this break, the administration of Silexan or placebo continued.

The study participants had to complete at least 2 cycles of oral contraception with Microgynon ${ }^{\circledR}$ in order to achieve steady state conditions. Since LNG highly binds to sex hormone-binding globulin (SHBG) in plasma, and $\mathrm{EE}$ induces the SHBG binding capacity, LNG levels were expected to be in a steady state after 2 cycles. Eligible subjects were then randomised to 2 additional cycles with coadministration of Silexan during the first and placebo during the second cycle, or vice versa (Table 1). Double-blind treatment was always started on the first day of the pill cycle following randomisation. Treatment compliance was monitored by recording each drug intake in a diary as well as by counting the unused medication. Furthermore, plasma levels of linalool, the main metabolite of Silexan, were determined at weekly intervals during randomised treatment.

\subsection{Study Schedule, Outcomes}

During randomised treatment, weekly visits were scheduled on days $7,14,21$, and 28 of each cycle. For each visit, a deviation of \pm 1 day was permitted. In addition, blood sampling for determining the pharmacokinetic (PK) parameters of EE and LNG was performed on 4 consecutive days starting on day $18 \pm 1$ day of each cycle: on each of these days EE and LNG trough levels were determined. Furthermore, blood samples for determining PK profiles were obtained at $0.5,1,1.5,2,3,4,6,8$, and $24 \mathrm{~h}$ after the intake of Microgynon ${ }^{\circledR}$ on the third and into the fourth day. The subjects were required to abstain from any food and beverages except for water after 22:00 h on the 2 nd day of sampling and received standardised meals on the 3rd day. After the end of the 2nd cycle during randomised treatment, a follow-up examination was scheduled to be performed within 7-14 days. The samples were analysed for the determination of EE, LNG, and linalool levels using a validated high-performance liquid chromatography (HPLC)tandem mass spectrometry (MS/MS) method and ConCalc for Windows (CCW; Integ $\mathrm{GmbH}$ ) software version 1.15.

The primary outcome measures for assessing potential pharmacological interactions between Silexan and the combination oral contraceptive were the area under the curve over a dosing interval of $\tau=24 \mathrm{~h}$ (AUC $\tau$ ) derived from the 24-h concentration-time curves for EE and LNG at steady state. Secondary outcome measures included the EE and LNG peak concentration $\left(C_{\max }\right)$, time to peak concentration $\left(t_{\max }\right)$, and trough levels. Ovarian follicle size measurements were performed through transvaginal ultrasound examinations at screening and at each weekly visit during randomised treatment, and the Hoogland score [20] was determined for each treatment cycle as a measure of ovarian activity. SHBG levels were determined at the end of the 3 rd week (i.e., end of Microgynon ${ }^{\circledR}$ intake) during each cycle.

Assessment of safety and tolerability was based on spontaneous reports of adverse events (AEs), physical examinations and safety laboratory measurements.

\subsection{Random Sequence Generation, Allocation Concealment, Implementation}

After subjects were determined as eligible for the trial, they were randomised to treatment with Silexan followed by placebo, or vice versa, at a ratio of 1:1. Fixed block randomisation was used; however, the investigator was not informed about the random block size until completion of the trial. A biometrician otherwise not involved in the trial generated the code using a validated computer program. Upon inclusion into randomised treatment, each subject received the lowest available number.

\subsection{Statistical Methods, Sample Size}

PK parameters were derived by non-compartmental methods using Phoenix WinNonlin ${ }^{\circledR}$ software (Certara, L.P., St 
Table 1 Study schedule

\begin{tabular}{|c|c|c|c|c|c|c|}
\hline \multirow{3}{*}{$\begin{array}{l}\text { Study period } \\
\text { Duration (days) }\end{array}$} & \multirow{3}{*}{$\begin{array}{l}\text { Screening: cycles } \\
1+2 \\
\text { Up to } 56\end{array}$} & \multicolumn{2}{|l|}{ Treatment: cycle 3} & \multicolumn{2}{|l|}{ Treatment: cycle 4} & \multirow{3}{*}{$\begin{array}{l}\text { Follow-up } \\
7-14\end{array}$} \\
\hline & & \multicolumn{2}{|l|}{28} & \multicolumn{2}{|l|}{28} & \\
\hline & & 21 & 7 & 21 & 7 & \\
\hline Treatment & Microgynon $^{\circledR}$ & $\begin{array}{l}\text { Microgynon }{ }^{\circledR}+\text { SIL or } \\
\text { PL }\end{array}$ & SIL or PL & $\begin{array}{l}\text { Microgynon }^{\circledR}+\text { PL or } \\
\text { SIL }\end{array}$ & PL or SIL & None \\
\hline $\begin{array}{l}\text { PK profile blood } \\
\text { samples }^{\mathrm{a}}\end{array}$ & & Days $3+4$ & & Days $3+4$ & & \\
\hline $\begin{array}{l}\mathrm{EE}+\mathrm{LNG} \text { trough } \\
\text { levels }\end{array}$ & & Days 18-21 & & Days 18-21 & & \\
\hline
\end{tabular}

a Samples were obtained at $0.5,1,1.5,2,3,4,6,8$, and $24 \mathrm{~h}$ after intake of Microgynon ${ }^{\circledR}$

$E E$ ethinyl estradiol, $L N G$ levonorgestrel, $P K$ pharmacokinetics, $P L$ placebo, SIL Silexan

Louis, MO, USA). $C_{\max }$ and $t_{\max }$ were read directly from the data, the AUC $\tau$ was derived by the linear trapezoidal rule, $t_{1 / 2}=(\ln 2) / \lambda_{\mathrm{z}}$, where the terminal rate constant was derived by log-linear regression, apparent clearance CL/ $f=\mathrm{AUC} \tau /$ dose, and apparent volume distribution $V_{\mathrm{z}} /$ $f=\lambda_{\mathrm{z}} \times \mathrm{CL} / f / \lambda_{\mathrm{z}}$.

PK measures determined from the EE and LNG concentration-time profiles were compared between Silexan and placebo using analysis of variance (ANOVA) models with main effects for sequence, subject within sequence, period, and treatment. Tests for $\mathrm{AUC} \tau$ and $C_{\max }$ were performed after $\log$ transformation, and for $t_{\max }$ on the original untransformed scale. Confidence intervals determined on the $\log$ scale were back-transformed into the original scale.

In the absence of other guidance, the assessment of the pharmacological interacting potential of Silexan was based on the same approach as when testing for bioequivalence [21]: the absence of a clinically relevant PK interaction between Silexan and EE or LNG was concluded if the $90 \%$ confidence intervals for the AUC $\tau$ ratios (Silexan/ placebo) determined from the ANOVA models were included within the standard 80-125\% equivalence range. Since the confidence intervals for the AUC $\tau$ ratios of both hormones were required to fall within the pre-specified equivalence range simultaneously, type I error level adjustment for multiple testing was not required.

Comparable ANOVA models were also applied to $C_{\max }$ and $t_{\max }$; however, these were interpreted descriptively. For SHBG concentration, an ANOVA model was fitted using the same factors after log-transformation of the dependent variable. All other interaction and safety measures were evaluated using methods of descriptive data analysis.

The sample size estimation was based on the assumption of a true within-subject coefficient of variation of $20 \%$ for $\ln (\mathrm{AUC} \tau)$ of both EE and LNG. When the true AUC $\tau$ ratio between Silexan and placebo is between 0.95 and 1.05 , a sample size of 20 subjects will have at least $80 \%$ power for rejecting the null hypothesis predicting an interaction between Silexan and EE or LNG according to the above criteria. In order to compensate for study participants who did not complete both treatment phases, a total of 24 subjects were to be randomised.

\section{Results}

\subsection{Recruitment, Participant Flow, Protocol Deviations}

Between November 2009 and May 2010, a total of 32 women were included and 24 were randomised and treated. All randomised subjects completed the study as scheduled.

All treated subjects were analysed for safety. Two subjects were excluded from all PK and pharmacodynamic (PD) analyses; one took prohibited concomitant medication and one missed one dose of Microgynon ${ }^{\circledR}$, which was considered a major protocol deviation since it could not be excluded that the dose might have been missed on the day before obtaining the PK profile. One other subject mistakenly received the investigational treatments in reverse order compared with the randomisation; however, she was included into all analyses and evaluated as treated. All decisions concerning the subjects' eligibility for the different analyses were made before code breaking.

\subsection{Sample Characteristics}

The randomised study participants were aged between 21 and 37 years (mean \pm standard deviation [SD] 27.3 \pm 4.1 years) and had a body mass index ranging between 19.3 and $26.8 \mathrm{~kg} / \mathrm{m}^{2}\left(22.2 \pm 2.0 \mathrm{~kg} / \mathrm{m}^{2}\right)$. All women were fertile and had already used hormonal contraception before inclusion. All participants were of Caucasian race, although study participation was open to all ethnic groups. Nine of the 24 women $(37.5 \%)$ were current smokers (up to a maximum of ten cigarettes per day allowed) and seven 
Table 2 Main pharmacokinetic parameters $(n=22)$

\begin{tabular}{lllll}
\hline & & AUC $\tau(\mathrm{pg} \times \mathrm{h} / \mathrm{ml})^{\mathrm{a}}$ & $C_{\max }(\mathrm{pg} / \mathrm{ml})^{\mathrm{a}}$ & $t_{\max }(\mathrm{h})^{\mathrm{b}}$ \\
\hline Ethinyl estradiol & Placebo & $937.4 \pm 265.8$ & $105.6 \pm 33.2$ & $1.5(1.0-3.0)$ \\
& Silexan & $911.7 \pm 263.3$ & $106.6 \pm 38.3$ & $1.5(0.9-3.0)$ \\
& Ratio or difference $90 \% \mathrm{CI}$ & $0.97(0.93-1.02)$ & $0.99(0.92-1.07)$ & $0.11(-0.15$ to 0.37$)$ \\
Levonorgestrel & Placebo & $94.3 \pm 34.6$ & $8.0 \pm 2.6$ & $1.0(0.5-1.6)$ \\
& Silexan & $90.3 \pm 37.7$ & $7.7 \pm 2.8$ & $1.1(1.0-3.0)$ \\
& Ratio or difference $90 \% \mathrm{CI}$ & $0.94(0.89-1.00)$ & $0.96(0.91-1.01)$ & $0.29(0.05-0.53)$ \\
\hline
\end{tabular}

a Mean \pm SD, back-transformed CI for ratio between marginal (geometric) means from ANOVA model, Silexan/placebo

b Median (range), confidence interval for difference between marginal (arithmetic) means from ANOVA model, Silexan-placebo ANOVA analysis of variation, $A U C \tau$ area under the concentration-time curve over a dosing interval of $\tau=24 \mathrm{~h}, C I$ confidence interval, $C_{m a x}$ peak concentration, $S D$ standard deviation, $t_{\max }$ time to $C_{\max }$

(29.2\%) were ex-smokers; 23 (95.8\%) drank alcohol occasionally. The most frequent diseases in medical history were myopia (ten subjects, $41.7 \%$ ) and headache (eight subjects, $33.3 \%$ ). In the physical examination performed at screening, none of the randomised subjects presented with findings from which an inference with the study procedures or outcomes was to be expected. Of note, none of the women had abnormal findings in the gynaecological examination.

\subsection{Treatment Compliance}

According to capsule counting, compliance with Silexan or placebo was $100 \%$ in 23 of the 24 subjects. One woman took one additional capsule during the first treatment period and left out one during the second. The analysis of linalool plasma concentrations confirmed that all participants had taken Silexan according to the randomisation, whereas the treatment sequence had been mixed up in one woman.

Of the 24 randomised participants, 22 took Microgynon ${ }^{\circledR}$ as prescribed. One missed one dose (and was therefore excluded from all PK and PD analyses), whereas another woman took one additional dose while under co-medication with placebo (by mistake two tablets at once).

\subsection{Pharmacokinetic and Pharmacodynamic Evaluation}

Figure 1 shows the plasma concentration-time profiles for EE and LNG during co-administration of Silexan or placebo. The numerical results are presented in Table 2.

For EE and LNG, the $90 \%$ confidence intervals for the AUC $\tau$ and $C_{\max }$ ratios between Silexan and placebo were completely included in the pre-specified equivalence range so that an influence of co-administration of Silexan on these PK measures could be excluded. Whereas the results do not indicate a significant influence of Silexan on $t_{\max }$ of $\mathrm{EE}$, the $t_{\max }$ of $\mathrm{LNG}$ was prolonged by an average of about $17 \mathrm{~min}$ (point estimate for the mean value difference), albeit without significantly affecting $C_{\max }$ or the $\mathrm{AUC} \tau$.

The results for the main PD outcomes and biomarkers are summarised in Table 3. The only case of an active follicle-like structure ( $>13 \mathrm{~mm}$ follicular growth accompanied by estradiol production) was observed during placebo treatment. Average follicle sizes decreased during Microgynon ${ }^{\circledR}$ intake until day 21 but showed an increase during the pill-free 4th week of the cycles. Mean values were similar under co-medication with Silexan and placebo; however, at three of the four postbaseline visits, the larger average for both follicles was observed during placebo treatment. Mean endometrial thickness was also comparable during both treatment phases.

Comparable mean levels for progesterone, estradiol, and SHBG were observed during both treatment phases (Table 3). Whereas progesterone showed only minor changes over time, estradiol decreased markedly until the end of the 2 nd week of the cycles and continued to decrease slightly during the 3rd week, whereas a sharp average increase was observed in the pill-free 4th week. During the first 3 weeks of each cycle, while administering Microgynon $^{\circledR}$, none of the women showed an estradiol level $>50 \mathrm{pg} / \mathrm{ml}$, and one woman had a progesterone level $>3 \mathrm{nmol} / \mathrm{l}$ on day 21 while under co-administration of placebo.

Individual values for the linalool concentrations indicate that the PK evaluation has been performed after a steady state was reached.

\subsection{Safety/Tolerability}

During randomised treatment, 36 AEs were reported by 17 of the 24 women $(70.8 \%)$ under co-administration of 
Fig. 1 Plasma concentrationtime profiles of EE (upper panel) and LNG (lower panel) over 28 days during treatment with Microgynon ${ }^{\circledR}$ plus placebo and Microgynon ${ }^{\circledR}$ plus Silexan (mean $\pm \mathrm{SD}$ ). $E E$ ethinyl estradiol, $L L O Q$ lower limit of quantification, $L N G$ levonorgestrel, $S D$ standard deviation
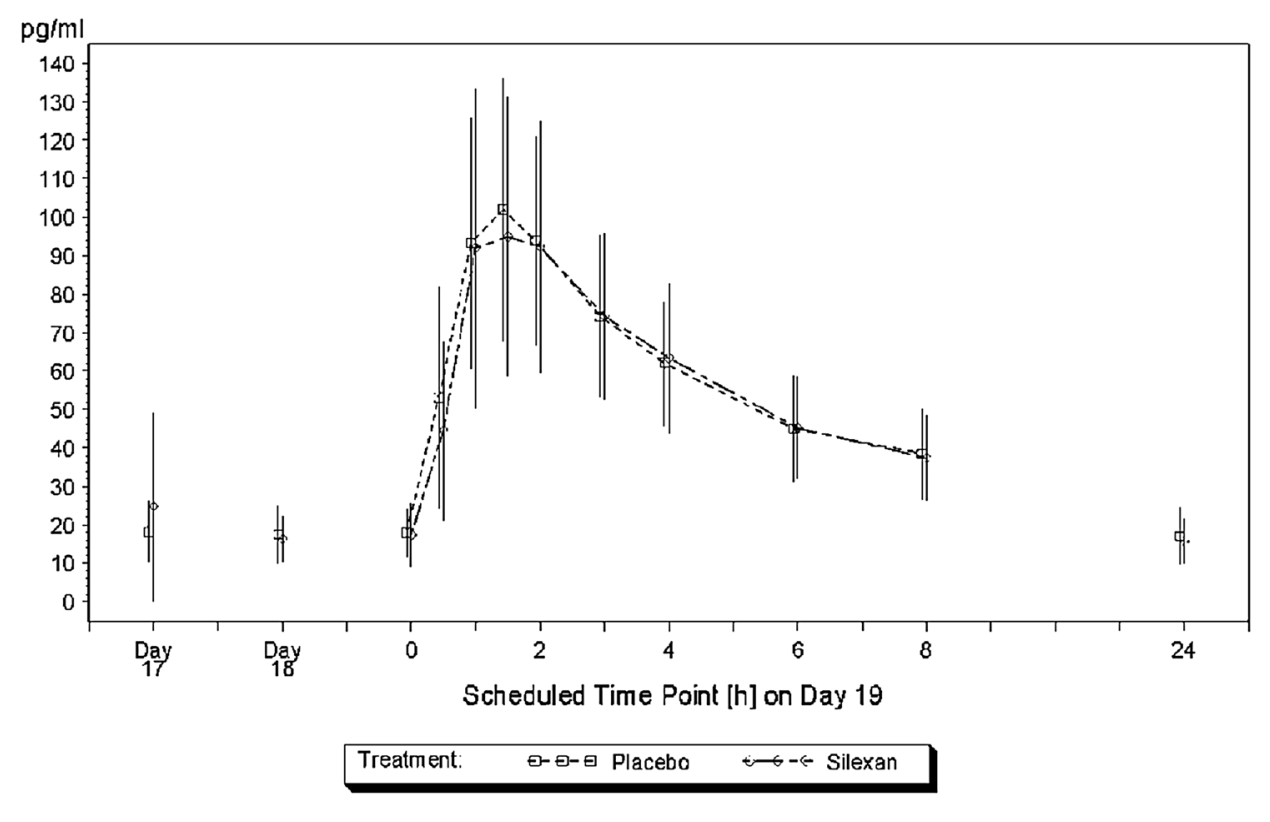

Whiskers show arithmetic mean +1 - standard deviation

Results below LLOQ (LLOQ $=5.111 \mathrm{pg} / \mathrm{ml}$ ) were considered as zero.

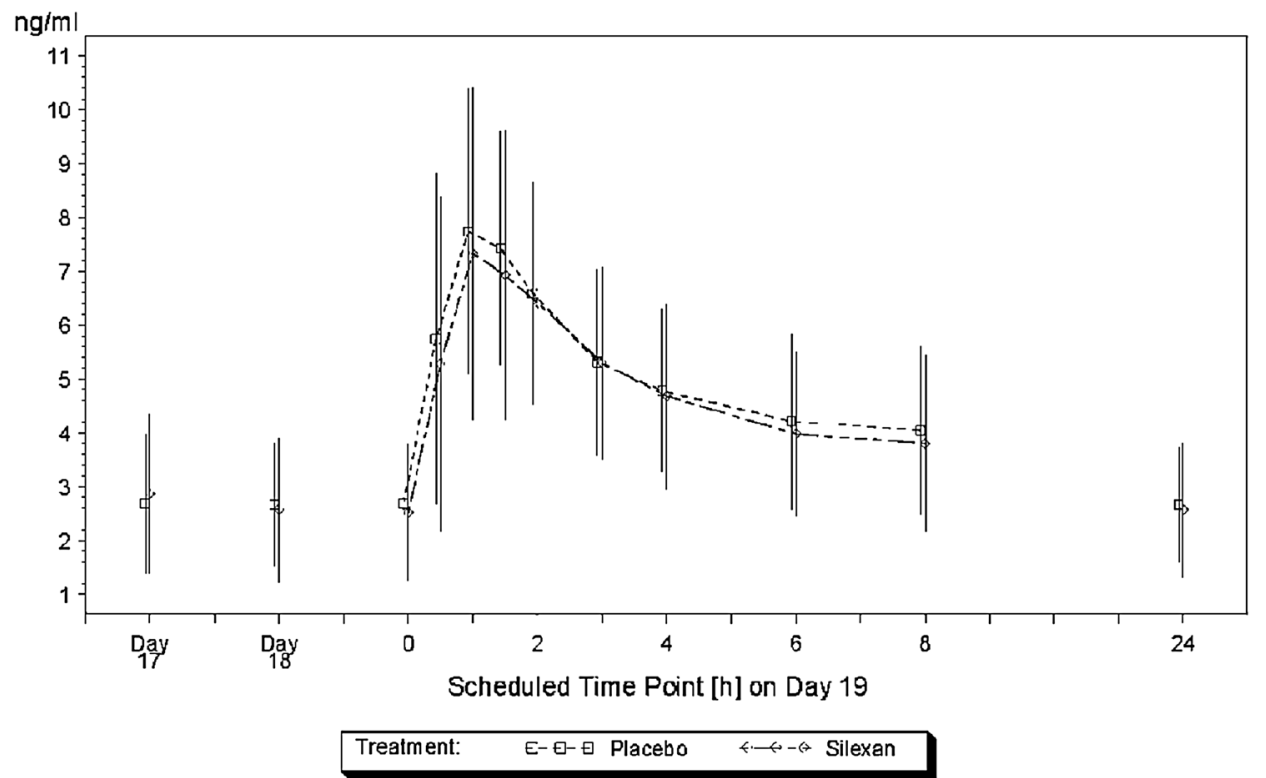

Whiskers show arithmetic mean $+/$ - standard deviation Results below LLOQ (LLOQ $=0.492 \mathrm{ng} / \mathrm{ml})$ were considered as zero.
Microgynon ${ }^{\circledR}$ and Silexan, whereas 23 events were reported by 16 subjects $(66.7 \%)$ in the Microgynon ${ }^{\circledR}$ plus placebo phase. All events were mild or moderate in intensity, and all were non-serious. AEs in which a causal relationship to the investigational treatment could not be excluded occurred in ten subjects during Microgynon ${ }^{\circledR}$ and Silexan treatment (gastrointestinal disorders, nine subjects; weight increased, one subject; headache, two subjects; and acne, one subject) as well as in two subjects during Microgynon ${ }^{\circledR}$ plus placebo treatment (headache and fatigue, one subject each). Safety laboratory measures reflected changes that were attributed to frequent blood sampling (e.g., anaemia) but were otherwise uneventful.

\section{Discussion}

It is important to investigate whether anxiolytic drugs may modify the bioavailability and the clinical efficacy of oral contraceptives with steroid hormones.

The study demonstrates that Silexan does not show clinically relevant pharmacological interactions with $\mathrm{EE}$ or 
Table 3 Summary of main pharmacodynamic outcomes

\begin{tabular}{|c|c|c|}
\hline & Placebo & Silexan \\
\hline \multicolumn{3}{|l|}{ Hoogland score $(n=22)$} \\
\hline No activity ${ }^{\mathrm{a}}$ & $20(90.9 \%)$ & $16(72.7 \%)$ \\
\hline Potential activity ${ }^{\mathrm{b}}$ & $1(4.5 \%)$ & $6(27.3 \%)$ \\
\hline Active follicle-like structure ${ }^{c}$ & $1(4.5 \%)$ & $0(0.0 \%)$ \\
\hline \multicolumn{3}{|l|}{ Follicle size, right $(\mathrm{mm})(n=22)$} \\
\hline Day 7 & $7.1 \pm 4.1$ & $6.6 \pm 2.0$ \\
\hline Day 14 & $6.1 \pm 3.6$ & $5.0 \pm 1.0$ \\
\hline Day 21 & $5.1 \pm 1.3$ & $4.8 \pm 0.8$ \\
\hline Day 28 & $6.9 \pm 1.5$ & $7.3 \pm 1.7$ \\
\hline \multicolumn{3}{|l|}{ Follicle size, left $(\mathrm{mm})(n=22)$} \\
\hline Day 7 & $6.4 \pm 1.7$ & $6.4 \pm 2.1$ \\
\hline Day 14 & $5.3 \pm 1.0$ & $5.0 \pm 0.8$ \\
\hline Day 21 & $4.9 \pm 0.9$ & $5.0 \pm 0.8$ \\
\hline Day 28 & $7.0 \pm 1.9$ & $6.7 \pm 1.7$ \\
\hline \multicolumn{3}{|c|}{ Endometrial thickness $(\mathrm{mm})(n=22)$} \\
\hline Day 7 & $4.1 \pm 1.1$ & $4.4 \pm 1.0$ \\
\hline Day 14 & $4.0 \pm 1.1$ & $4.5 \pm 1.5$ \\
\hline Day 21 & $4.5 \pm 1.8$ & $4.1 \pm 1.1$ \\
\hline Day 28 & $3.6 \pm 1.1$ & $3.8 \pm 1.2$ \\
\hline \multicolumn{3}{|l|}{ Progesterone $(\mathrm{nmol} / \mathrm{l})(n=24)$} \\
\hline Day 7 & $1.2 \pm 0.6$ & $1.2 \pm 0.6$ \\
\hline Day 14 & $1.2 \pm 0.6$ & $1.1 \pm 0.5$ \\
\hline Day 21 & $1.1 \pm 0.7$ & $1.2 \pm 0.6$ \\
\hline Day 28 & $1.3 \pm 0.7$ & $1.3 \pm 0.7$ \\
\hline \multicolumn{3}{|l|}{ Estradiol $(\mathrm{pg} / \mathrm{ml})(n=24)$} \\
\hline Day 7 & $32.9 \pm 114.6$ & $31.2 \pm 107.7$ \\
\hline Day 14 & $8.1 \pm 7.2$ & $10.9 \pm 6.6$ \\
\hline Day 21 & $7.3 \pm 6.0$ & $7.5 \pm 5.6$ \\
\hline Day 28 & $44.9 \pm 37.8$ & $42.4 \pm 32.0$ \\
\hline \multicolumn{3}{|l|}{ SHBG $(\mathrm{nmol} / \mathrm{l})(n=24)$} \\
\hline Day 21 & $112.7 \pm 40.0$ & $113.5 \pm 40.9$ \\
\hline
\end{tabular}

Data are presented as mean \pm SD or number $(\%)$

${ }^{\text {a }}$ Follicle size $\leq 10.0 \mathrm{~mm}$

b Follicle size 10.1-13.0 mm

${ }^{\mathrm{c}}$ Follicle size $>13.0 \mathrm{~mm}$, progesterone $\leq 5 \mathrm{nmol} / \mathrm{l}$, estradiol $>30 \mathrm{pg} /$ $\mathrm{ml}$

$S D$ standard deviation, $S H B G$ sex hormone-binding globulin

LNG, which are the active ingredients of Microgynon ${ }^{\circledR}$ as well as of many other widely used oral contraceptives. According to the lower bound of the $90 \%$ confidence intervals for the AUC $\tau$ ratios of Silexan and placebo, a reduction of relative EE bioavailability by more than $7 \%$, as well as a reduction of relative LNG bioavailability by more than $11 \%$, can be excluded with a probability of $95 \%$, and at least $92 \%$ of the maximum EE concentration, as well as $91 \%$ of the maximum LNG concentration, are preserved during co-administration of the herbal drug. For LNG, a slight delay in reaching the LNG peak level was observed, but this did not affect the relative bioavailability of the hormonal contraceptives.

Smoking may alter the PK properties of oral contraceptive steroids. Since about one-third of the women in the study sample were mild smokers (subjects smoking more than ten cigarettes per day were excluded from participation), this might have contributed to large inter-individual variability in plasma concentrations, notably in EE. However, the inter- and intra-individual variability of the $\mathrm{EE}$ plasma levels in our trial was comparable with the literature [22] and, moreover, higher variability would have biased the data towards an acceptance of the null hypothesis predicting an interaction between Silexan and EE and/ or LNG. Since the null hypothesis could be rejected and an interaction could be excluded in accordance with the prespecified criteria, an introduction of bias due to the inclusion of mild smokers can also be excluded.

Progesterone, estradiol, and SHBG level monitoring also did not indicate an impairment of the contraceptive efficacy of Microgynon ${ }^{\circledR}$ during co-administration of Silexan. Throughout the entire cycle of randomised treatment, the average levels of these biomarkers during co-administration of Silexan were always in the range of those observed under placebo treatment.

Silexan had no appreciable effect on mean endometrial thickness and follicle size. The measured individual follicle sizes were always within the range expected during adequate ovarian suppression [23], and a follicle size exceeding a threshold value of $13 \mathrm{~mm}$ was observed only once in a woman receiving placebo.

AEs observed during this trial in healthy volunteers were never more than moderately severe and temporary; abnormal laboratory values were more often related to the study procedures (e.g., to frequent blood sampling) than to study medication intake. Among the events assessed to be potentially attributable to Silexan, the only effect that was observed in more than one subject but also not during placebo treatment was eructation. Mild gastrointestinal disorders are among the known side effects of Silexan, but were always tolerable and did not interfere with treatment compliance.

In conclusion, Silexan, at a dose of $160 \mathrm{mg} / \mathrm{day}$, corresponding to twice the currently recommended dose, did not adversely affect the relative bioavailability and the suppressive efficacy on hormonal and ovarian status of the oral combination contraceptive Microgynon ${ }^{\circledR}$ whose active ingredients are EE and LNG. Silexan was well tolerated.

Acknowledgments This study was work for hire supported by Dr. Willmar Schwabe GmbH \& Co. KG, Karlsruhe, Germany (sponsor). $\mathrm{AD}$ and SS are employees of Dr. Willmar Schwabe GmbH \& Co. KG. No further conflict of interest is declared. Medical writing support was provided by Andreas Völp, psy consult scientific services, Frankfurt, Germany. 
Open Access This article is distributed under the terms of the Creative Commons Attribution Noncommercial License which permits any noncommercial use, distribution, and reproduction in any medium, provided the original author(s) and the source are credited.

\section{References}

1. European directorate for the quality of medicines and healthcare. Lavender oil (Lavandulae aetheroleum). European Pharmacopoeia 5.0. 2005. p. 1894.

2. Kasper S, Gastpar M, Müller WE, Volz HP, Möller HJ, Dienel A, et al. Silexan, an orally administered Lavandula oil preparation, is effective in the treatment of 'subsyndromal' anxiety disorder: a randomized, double-blind, placebo controlled trial. Int Clin Psychopharmacol. 2010;25(6):277-87. doi:10.1097/YIC.0b013e328 $33 \mathrm{~b} 3242$.

3. Woelk H, Schläfke S. A multi-center, double-blind, randomised study of the Lavender oil preparation Silexan in comparison to Lorazepam for generalized anxiety disorder. Phytomedicine. 2010;17(2):94-9.

4. Setzer WN. Essential oils and anxiolytic aromatherapy. Nat Prod Commun. 2009;4(9):1305-16.

5. Kessler RC, Chiu WT, Demler O, Merikangas KR, Walters EE. Prevalence, severity, and comorbidity of 12-month DSM-IV disorders in the National Comorbidity Survey Replication. Arch Gen Psychiatry. 2005;62(6):617-27. doi:10.1001/archpsyc.62.6. 617.

6. Wittchen HU, Jacobi F, Rehm J, Gustavsson A, Svensson M, Jonsson B, et al. The size and burden of mental disorders and other disorders of the brain in Europe 2010. Eur Neuropsychopharmacol. 2011;21(9):655-79. doi:10.1016/j.euroneuro.2011.07. 018.

7. Bekker MH, van Mens-Verhulst J. Anxiety disorders: sex differences in prevalence, degree, and background, but genderneutral treatment. Gend Med. 2007;4(Suppl B):S178-93.

8. Somers JM, Goldner EM, Waraich P, Hsu L. Prevalence and incidence studies of anxiety disorders: a systematic review of the literature. Can J Psychiatry. 2006;51(2):100-13.

9. Scott KM, Von Korff M, Alonso J, Angermeyer M, Bromet EJ, Bruffaerts R, et al. Age patterns in the prevalence of DSM-IV depressive/anxiety disorders with and without physical co-morbidity. Psychol Med. 2008;38(11):1659-69. doi:10.1017/S00332 91708003413.

10. Back DJ, Orme ML. Pharmacokinetic drug interactions with oral contraceptives. Clin Pharmacokinet. 1990;18(6):472-84.

11. Shenfield GM. Oral contraceptives. Are drug interactions of clinical significance? Drug Saf. 1993;9(1):21-37.
12. Rendic S. Summary of information on human CYP enzymes: human P450 metabolism data. Drug Metab Rev. 2002;34(1-2): 83-448. doi:10.1081/DMR-120001392.

13. Committee for Proprietary Medical Products. Note for guidance on the investigation of bioavailability and bioequivalence. London: European Agency for the Evaluation of Medicinal Products 2001 (July 26, 2001). Report No.: CPMP/EWP/QWP/1401/98.

14. Thomsen M, Gennat H, Schmidt A. Herb-drug interaction. In: Watson RR, Preedy VR, editors. Botanical medicine in clinical practice. 3rd ed. Wallingford: CABI; 2008. p. 859-68.

15. Doroshyenko O, Rokitta D, Zadoyan G, Klement S, Schlafke S, Dienel A, et al. Drug cocktail interaction study on the effect of the orally administered lavender oil preparation silexan on cytochrome P450 enzymes in healthy volunteers. Drug Metab Dispos. 2013;41(5):987-93. doi:10.1124/dmd.112.050203.

16. Williams JA, Hyland R, Jones BC, Smith DA, Hurst S, Goosen $\mathrm{TC}$, et al. Drug-drug interactions for UDP-glucuronosyltransferase substrates: a pharmacokinetic explanation for typically observed low exposure (AUCi/AUC) ratios. Drug Metab Dispos. 2004;32(11):1201-8. doi:10.1124/dmd.104.000794.

17. Kasper S, Gastpar M, Müller WE, Volz H-P, Möller H-J, Schläfke S, et al. Lavender oil preparation Silexan is effective in generalized anxiety disorder-a randomized, double-blind comparison to placebo and paroxetine. Int J Neuropsychopharmacol. 2014;17(6):859-69. doi:10.1017/S1461145714000017.

18. Kothare PA, Seger ME, Northrup J, Mace K, Mitchell MI, Linnebjerg $\mathrm{H}$. Effect of exenatide on the pharmacokinetics of a combination oral contraceptive in healthy women: an open-label, randomised, crossover trial. BMC Clin Pharmacol. 2012;12:8. doi:10.1186/1472-6904-12-8.

19. David OJ, Ocwieja M, Meiser K, Emotte C, Jakab A, Wemer J, et al. Pharmacokinetics of fingolimod (FTY720) and a combined oral contraceptive coadministered in healthy women: drug-drug interaction study results. Int J Clin Pharmacol Ther. 2012;50(8): 540-4. doi:10.5414/CP201675.

20. Hoogland HJ, Skouby SO. Ultrasound evaluation of ovarian activity under oral contraceptives. Contraception. 1993;47(6): 583-90.

21. Committee for Medicinal Products for Human Use. Guideline on the investigation of bioequivalence. London: European Medicines Agency; 2010. Report No.: CPMP/EWP/QWP/1401/98 Rev. 1/ Corr Contract No.: CPMP/EWP/QWP/1401/98 Rev. 1/ Corr.

22. Stanczyk FZ, Archer DF, Bhavnani BR. Ethinyl estradiol and 17beta-estradiol in combined oral contraceptives: pharmacokinetics, pharmacodynamics and risk assessment. Contraception. 2013;87(6):706-27. doi:10.1016/j.contraception.2012.12.011.

23. Duijkers IJ, Klipping C, Verhoeven $\mathrm{CH}$, Dieben TO. Ovarian function with the contraceptive vaginal ring or an oral contraceptive: a randomized study. Hum Reprod. 2004;19(11):2668-73. doi:10.1093/humrep/deh493. 